\title{
Experimentação no ensino de Física Moderna: efeito fotoelétrico com lâmpada néon e $\operatorname{LEDs}^{+*}$
}

\author{
Dario Eberhardt ${ }^{1}$ \\ João Bernardes da Rocha Filho ${ }^{2}$ \\ Regis Alexandre Lahm $^{3}$ \\ Pontifícia Universidade Católica do Rio Grande do Sul \\ Pedro Barros Baitelli ${ }^{4}$ \\ Aluno da Escola Monteiro Lobato \\ Porto Alegre - RS
}

\section{Resumo}

O artigo apresenta uma experimentação destinada ao ensino de Física Moderna no Ensino Médio, especificamente o Efeito Fotoelétrico, e visa a instrumentalizar o professor ou servir como inspiração para a proposição de atividades didáticas. A experimentação descrita se funda na exposição de uma lâmpada néon às luzes de diferentes comprimentos de onda emitidas por LEDs variados. Mede-se a corrente fotoelétrica entre os eletrodos da lâmpada néon, verificando-se que esta possui sentido definido; que o efeito ocorre quando o comprimento de onda da luz aplicada é menor que determinado limite, e; que a intensidade da corrente fotoelétrica depende da intensidade da luz aplicada, em acordo com o modelo científico atual do fenômeno. São discutidas partes da história do Efeito Fotoelétrico, características de experimentos assemelhados que utilizam lâmpadas de luz ultravioleta, a função trabalho dos metais dos eletrodos e a energia de ionização dos gases no interior da lâmpada.

Palavras-chave: Ensino de Física; Efeito Fotoelétrico; Experimentação; Lâmpada néon; LED.

\footnotetext{
+ Experimentation in the teaching of Modern Physics: photoelectric effect with neon lamp and LEDs

* Recebido: dezembro de 2016.

Aceito: agosto de 2017.

${ }^{1}$ E-mail: dario.eberhardt@pucrs.br; ${ }^{2}$ E-mail: jbrfilho@pucrs.br; ${ }^{3}$ E-mail: lahm@pucrs.br,

${ }^{4}$ E-mail: pb.atm55@gmail.com
} 


\begin{abstract}
The article presents an experiment aimed at the teaching of Physics in High School, specifically the Photoelectric Effect, and it aims to support the teacher or serve as an inspiration for the proposition of other didactic activities. The experimentation consists on the exposure of a neon lamp to the lights of different wavelengths emitted by varied LEDs. The photoelectric current is measured on electrodes of the neon lamp, verifying that it has definite direction; the effect occurs when the wavelength of the applied light is less tan a certain limit, and; the intensity of the photoelectric current depends on the intensity of the light applied, in agreement with the current scientific model of the phenomenon. This text also includes many decisive moments of the history of the Photoelectric Effect, characteristics of similar experiments using ultraviolet light, the electron work function of the metals of the electrodes and the ionization energy of the gases inside the lamp.
\end{abstract}

Keywords: Physics Teaching; Photoelectric Effect; Experimentation; Néon Lamp; LED.

\title{
I. Introdução e breve reconstrução histórica do efeito fotoelétrico
}

O presente artigo descreve uma descoberta experimental dos autores sobre a viabilidade de lâmpadas néon serem utilizadas como sensores de luz em uma montagem destinada ao ensino do Efeito Fotoelétrico, mais especificamente como uma alternativa às antigas células a vácuo, que atualmente são fabricadas apenas artesanalmente e a custos que as tornam proibitivas para o uso didático.

Além disso, o artigo também descreve uma montagem experimental relativamente simples que utiliza LEDs de diversos comprimentos de onda como fontes de luz para a excitação da lâmpada néon, que pode ser utilizada para determinação experimental aproximada da frequência de corte do metal dos eletrodos da lâmpada, do sentido da corrente fotoelétrica e da dependência desta em relação à intensidade da luz incidente.

Nesse sentido, o conhecimento acerca dos acontecimentos que levaram à descoberta experimental e à descrição física do Efeito Fotoelétrico pode ser útil ao professor do Ensino Médio interessado em contextualizar o tema, pois o uso da história da ciência é um instrumento auxiliar para o ensino da física (GIL PÉREZ, 1993; PEDUZZI, 2001; MARTINS, 2008). Neste artigo, escolheu-se oferecer ao professor um relato sintético de alguns fatos relacionados à descoberta das radiações infravermelha e ultravioleta (UV), por Willian Herschel, em 1800, e por 
Johann Wilhelm Ritter, em 1801, respectivamente, como um incentivo ao uso dessas informações no processo educativo, seguido de informações pontuais dos trabalhos de Heinrich Hertz e Albert Einstein, no campo do Efeito Fotoelétrico, em si.

Essa abordagem, entretanto, não deve ser considerada completa ou única, pois trazer os fatos históricos de relevância relacionados ao ensino de certo conteúdo científico pode ser um desafio repleto de controvérsias. O problema básico é a questão da historicidade, ou seja, da colocação dos fatos em perspectiva, o que exige conhecimento e discernimento, além de certo grau de escolha pessoal, que tem seu papel na medida em que o professor assume-se como autor de seu trabalho educativo. Uma discussão mais completa, profunda e interessante sobre a historicidade na descoberta do Efeito Fotoelétrico, que inclui uma crítica às contribuições de Hertz, pode ser obtida em Mangilli (2012), entre outras fontes confiáveis apresentadas nas referências.

Sinteticamente, John Frederick William Herschel, um astrônomo inglês nascido em 1792, trabalhava com a luz dispersada em prismas, projetando os feixes coloridos sobre termômetros, e verificou que mesmo em posições que precediam o vermelho no espectro projetado aquém da borda vermelha do espectro visível - produzia-se aquecimento. Deduziu que também ali havia luz, embora invisível ao olho humano (OLIVEIRA; SILVA, 2014). Essa faixa do espectro, constatada experimentalmente pelo efeito térmico que produz, foi chamada de infravermelho.

Mais tarde, Johann Wilhelm Ritter, um físico alemão nascido em 1776, investigava o efeito das mesmas luzes dispersadas por prismas, mas não projetadas sobre termômetros, e sim sobre a substância química cloreto de prata. A luz tem a propriedade de escurecer esse sal, e Ritter sabia que o escurecimento se tornava mais rápido conforme a substância era exposta a feixes luminosos mais deslocados para o lado azul do espectro. Em seus experimentos, o sal colocado além da faixa violeta da luz dispersada, em uma região do espectro onde parecia não incidir luz, continuava escurecendo rapidamente. Ritter concluiu que ali havia também uma luz que, embora invisível, produzia efeitos físicos que a evidenciavam (BERG, 2008). Essa luz foi denominada de UV.

As pesquisas de Herschel e Ritter compõem parte da história do desenvolvimento da fotografia, que passa também pelos trabalhos do inventor francês Joseph Nicéphore Niépce, por volta de 1826, e do físico e artista, também francês, Louis Jacques Mandé Daguerre, um pouco mais tarde. O próprio cloreto de prata - usado por Ritter - veio a ser utilizado como elemento sensível à luz em papéis fotográficos pelo cientista inglês William Fox Talbot, em 1839.

Já ao redor de 1887, o físico alemão Heinrich Hertz tentava provar experimentalmente a existência das ondas eletromagnéticas, previstas quase trinta anos antes pelo físico escocês James Clerk Maxwell. Em dado momento, Hertz percebeu que a ocorrência de arcos voltaicos em circuitos de seu laboratório parecia induzir o surgimento de faíscas entre dois eletrodos colocados em um circuito ressonante próximo, com linha de visada direta (NIAZ et al., 2010). 
Após algumas tentativas, Hertz percebeu que a colocação de obstáculos entre os dois circuitos reduzia ou eliminava o fenômeno, e que superfícies metálicas podiam redirecionar a visada, chegando à conclusão que havia criado um sistema emissor-receptor de ondas eletromagnéticas, que se comportavam como a luz.

Hertz também percebeu que, ao serem iluminados pela luz de um arco-voltaico, dois eletrodos próximos, energizados com cargas opostas e quase ao limite da rigidez dielétrica do ar que os separava, tendiam a dar início a uma faísca. Ele concluiu que esse fenômeno provavelmente não se devia à transmissão das ondas eletromagnéticas na faixa que depois viria a ser conhecida como ondas de rádio, que ele estudava, mas sim à luz UV emitida pelo arco-voltaico, pois tanto obstáculos condutores quanto dielétricos impediam ou reduziam a intensidade do fenômeno.

Hertz descobriu que a aproximação de uma vela acesa aos eletrodos energizados também produzia o faiscamento, que podia ser atenuado pela interposição - entre a vela e os eletrodos - de uma folha de mica, mas não por um cristal de quartzo, o que sugeriu que esses materiais, embora transparentes à luz visível, apresentavam diferentes absorções da luz UV (MANGILLI, 2012). Apesar disso, Hertz estava voltado a provar as equações de Maxwell, de modo que não investigou a fundo o fenômeno, deixando apenas registrada sua observação (BARROS; SOARES, 2017). Por isso, há críticas sobre se Hertz deve, ou não, ser considerado o descobridor do Efeito Fotoelétrico.

Essa observação de Hertz foi confirmada pelo físico alemão Wilhelm Hallwachs, apenas alguns meses após, quando este percebeu que objetos constituídos de certos metais ficavam positivamente carregados quando suas superfícies eram expostas à luz UV - fato que foi explicado pelo Nobel de Física de 1905, o alemão Philipp von Lenard, como sendo devido à expulsão de partículas da superfície metálica iluminada (WHEATON, 1978). Um ano mais tarde, o físico inglês Joseph John Thomson propôs que essas partículas eram, na verdade, elétrons.

Essa sequência de acontecimentos contextualiza a enunciação da lei matemática do Efeito Fotoelétrico, no início do século XX, pelo físico alemão Albert Einstein, feito pelo qual foi premiado com o Nobel de Física em 1916. Einstein elaborou uma teoria que incluía o entendimento da luz como sendo constituída por feixes de unidades de energia independentes que ele denominou lightquanta (NIAZ et al., 2010), que passaram a ser chamados de fótons somente em 1926, pelo químico americano Gilbert Newton Lewis, em um texto denominado "The conservation of photons", publicado na revista Nature (OKUN, 2008).

Para Einstein, cada lightquantum podia interagir com um único elétron atômico de cada vez, transferindo a este uma quantidade definida de energia, cujo valor podia ser calculado como o produto da constante de Planck pela frequência correspondente à onda associada ao lightquantum. Em um feixe de luz monocromática, portanto, todos os lightquanta têm a mesma energia. Uma luz mais intensa correspondia a uma taxa maior de lightquanta, mas não maior energia individual de cada lightquantum. Se um feixe de luz fosse projetado sobre uma superfície metálica e a energia dos lightquanta desse feixe fosse superior a certo valor característico 
próprio daquele metal, seus elétrons superficiais eram ejetados da superfície metálica com a energia excedente, mas estes poderiam ser freados por um potencial negativo aplicado em um eletrodo adequadamente colocado em seu caminho (Eq. 1). Ou seja:

$$
\mathrm{E}=\mathrm{h} v=\mathrm{KE}_{\max }+\mathrm{W}_{0}
$$

sendo $\mathrm{h}$ a constante de Planck, $v$, a frequência da radiação incidente, "[...] KEmax, a energia cinética máxima dos fotoelétrons emitidos e $\mathrm{W}_{0}$, a energia necessária para removê-los da superfície do material (a função trabalho). A energia E é aquela fornecida pelo quantum de luz conhecido como fóton" (CERNICCHIARO et al., 2006, p. 22).

No entanto, a proposição do lightquantum não foi aceita de imediato. Os primeiros indícios experimentais da validade das ideias de Einstein sobre o Efeito Fotoelétrico só vieram em 1912, com os trabalhos dos físicos Arthur Llewelyn Hughes, Owen Willians Richardson e Karl Taylor Compton, e a primeira comprovação experimental ocorreu por volta de 1915, com o Nobel de Física americano Robert Andrews Millikan, que criou a expressão potencial de freamento (SOARES, 2016) e mediu a frequência de corte prevista por Einstein, assim como verificou a linearidade da relação do potencial de freamento com a frequência da radiação incidente no metal.

\section{O ensino do Efeito Fotoelétrico no Ensino Médio}

O Efeito Fotoelétrico, dada sua importância científica e tecnológica, é usualmente ensinado no contexto da Física Moderna, no final do Ensino Médio. Tentando superar métodos meramente transmissivos, alguns professores usam recursos computacionais instrutivos em relação à dinâmica do fenômeno, enquanto permitem certo grau de interatividade (VEIT, 1987; OSTERMANN; RICCI, 2005; OLIVEIRA CARDOSO; DICKMAN, 2012; SILVA, 2012). Contando com condições materiais adequadas, porém, um experimento concreto sobre este ou qualquer outro conteúdo da Física - uma ciência experimental - pode ser decisivo na aprendizagem (CARRASCOSA et al., 2006) e aumenta a chance de que os estudantes construam significados quanto ao fenômeno estudado. Isso ocorre porque os significados surgem como resposta ao vínculo dos conteúdos com o mundo mental do estudante (MENEGOTTO; ROCHA FILHO, 2008), e a experimentação concreta, assim como a virtual, contribui para essa vinculação.

Para a realização de experimentos ou demonstrações sobre o Efeito Fotoelétrico, porém, há poucas alternativas fora dos conjuntos prontos, vendidos por empresas fabricantes de materiais instrucionais. Alternativamente, uma das formas mais simples e seguras de usar a experimentação, nesse caso, envolve expor à luz do Sol uma placa de zinco eletrizada negativamente, ligada a um eletroscópio de folhas (SILVA, 2015). A radiação UV contida na luz solar extrai elétrons da placa, neutralizando-a, o que é deduzido pela reaproximação das folhas do 
eletroscópio. Ao abrigo do Sol a neutralização ocorre mais lentamente. Supondo que os estudantes tenham sido apresentados ao uso do eletroscópio, o experimento da placa de zinco tem em seu desfavor apenas a necessidade da luz solar, o que impede seu uso à noite ou em dias nublados.

Outras proposições substituíram a luz solar pela luz emitida por lâmpadas próprias para emissão de UV ou pelos bulbos internos de lâmpadas de vapor de mercúrio de alta pressão, associada a diferentes tipos de elementos sensores, como os que foram apresentados por Arruda e Toginho (1991), Rocha Filho, Salami e Hillebrand (2006) e Paranhos, Lopez-Richard e Pizani (2008). São experimentos mais complexos que, no entanto, favorecem a contextualização e envolvem materiais do cotidiano dos estudantes.

Experimentos com lâmpadas, entretanto, exigem grau mais elevado de controle do professor, pois há risco de ocorrerem danos aos olhos com poucos minutos de exposição. A título de exemplo, os bulbos internos das lâmpadas de vapor de mercúrio de alta pressão têm potências mínimas da ordem de $10^{2} \mathrm{~W}$ e emitem cerca de $20 \%$ de sua radiação na forma de UV (UNICAMP, s/a), suficiente para converter os gases do ar em quantidades não desprezíveis de ozônio e óxido nitroso - que são perigosos. Além disso, esses bulbos atingem temperaturas acima de $300^{\circ} \mathrm{C}$ e usam reatores para acendimento, que são caros e pesados.

Em face dessas dificuldades, a experimentação proposta neste artigo foi desenvolvida para ser utilizada no ensino qualitativo do Efeito Fotoelétrico no Ensino Médio com vista a:

a) Evidenciar a ocorrência do Efeito Fotoelétrico, estimando experimentalmente a frequência de corte do material superficial dos eletrodos das lâmpadas néon, assim como a dependência da corrente fotoelétrica em relação à intensidade da luz emitida pelos LED;

b) Ser segura, permitindo o manuseio pelos estudantes, sem necessidade de supervisão, treinamento especializado, uso de espaços especiais ou equipamentos de proteção individual;

c) Ser vinculada ao cotidiano dos estudantes, utilizando componentes comuns em equipamentos eletroeletrônicos;

d) Ser de realização simples, de baixo custo e adaptável às condições da maioria dos laboratórios escolares;

e) Prescindir do uso da luz solar, permitindo sua aplicação em classes noturnas, dias nublados ou salas fechadas, e;

f) Ser propícia à contextualização já que, por exemplo, os estudantes podem usar a lâmpada néon para identificar a presença de UV na luz solar, que é uma preocupação disseminada na atualidade em virtude da redução da camada de ozônio na alta atmosfera do polo sul do planeta.

\section{Compreendendo as lâmpadas néon miniatura}

A lâmpada néon miniatura é uma lâmpada de descarga gasosa de baixa pressão e cátodo frio, constituída essencialmente por um bulbo de vidro contendo dois eletrodos metálicos isolados entre si. O bulbo é tipicamente preenchido por uma mistura de 99,5\% de gás néon e 
0,5 \% de gás argônio, este último usado para reduzir a tensão de acendimento (GENERAL ELECTRIC, 1966). O gás néon existe em uma proporção aproximada de 0,0018 \% (em massa) na atmosfera terrestre (MACKENZIE; MACKENZIE, 1995), e foi isolado inicialmente a partir do fracionamento do argônio, enquanto a lâmpada néon foi inventada em 1920 por Daniel McFarlan Moore - um engenheiro americano que trabalhou para o inventor e empresário americano Thomas Alva Edison. Informações sobre as características de funcionamento e construção das lâmpadas néon não são encontradas em fontes acadêmicas atualizadas, devendo ser procuradas nos manuais de fabricantes ou bibliografias antigas.

Essa lâmpada foi empregada principalmente como luz indicativa de funcionamento nos equipamentos eletroeletrônicos da era anterior ao surgimento dos LEDs, e até hoje é aplicada para este fim em eletroportáteis não eletrônicos que operam em condições especiais de temperatura, como aquecedores de ambiente, cafeteiras e torradeiras elétricas, por exemplo. As lâmpadas néon são caracterizadas por serem pequenas, de baixo custo, terem longa vida útil e alta imunidade a surtos de tensão, resistência a altas temperaturas e simplicidade de ligação à rede elétrica de corrente alternada. Além disso, lâmpadas néon ainda são usadas em decoração, em chaves-teste para eletricistas, em reguladores de potência (dimmers) e em circuitos eletrônicos osciladores de relaxação de baixa frequência. A luz produzida nas lâmpadas néon é de cor vermelho alaranjada, de baixa intensidade, trabalhando com correntes desde um décimo até uma dezena de miliamperes.

Uma fotografia de uma lâmpada néon do modelo NE2H, usada no experimento aqui descrito, é mostrada na Fig. 1. Externamente, o bulbo de vidro da lâmpada é cilíndrico, fechado por prensagem na parte dos terminais, e por fusão na parte superior, e tem aproximadamente $15 \mathrm{~mm}$ de comprimento e $8 \mathrm{~mm}$ de diâmetro. Os eletrodos metálicos, internos ao bulbo, têm formato de bastão, medindo aproximadamente $5 \mathrm{~mm}$ de comprimento e $1 \mathrm{~mm}$ de diâmetro, e o metal e o tratamento empregados em sua confecção não são divulgados pelos fabricantes. Os eletrodos internos se ligam ao circuito por meio de terminais metálicos soldáveis com aproximadamente $30 \mathrm{~mm}$ de comprimento.

Fig. 1 - Lâmpada NE2H utilizada no experimento. (Fonte: os autores) 
A lâmpada néon tem comportamento elétrico similar ao dos demais tipos de lâmpadas de descarga gasosa comerciais (mercúrio, sódio, iodetos metálicos e xenônio), havendo uma tensão mínima necessária para iniciar a condução elétrica entre os eletrodos. Para tensões iniciais menores que este valor mínimo a lâmpada néon permanece apagada e apresenta circuito aberto entre seus terminais. Quando a tensão mínima é aplicada, porém, elétrons térmicos são acelerados até uma velocidade crítica, ionizando a mistura gasosa. A partir daí a corrente elétrica passa a ser limitada pela impedância da fonte de energia - usualmente a resistência de um resistor colocado em série com um dos eletrodos (LEYSHON, 1930).

A tensão mínima de acendimento varia com a composição superficial, as dimensões e o afastamento dos eletrodos e a composição e pressão da atmosfera interna, além de uma lista de variáveis externas, como a temperatura ambiente e a incidência de raios X, UV e raios cósmicos (GENERAL ELECTRIC, 1966). Até alguns anos depois da metade do século XX os eletrodos de algumas lâmpadas néon recebiam uma camada de compostos radioativos para que acendessem com tensões ainda menores (ibidem).

Ao acender, a corrente elétrica produz uma queda de tensão no resistor de limitação, fazendo com que a DDP nos terminais da lâmpada néon caia abaixo da sua tensão de acendimento. Isso implica que a tensão de manutenção da lâmpada néon, ou seja, a tensão mínima necessária para mantê-la acesa, é menor do que a tensão mínima para fazê-la acender. A curva de tensão elétrica versus corrente elétrica em lâmpadas de descarga gasosa, incluindo as de gás néon, tem esse comportamento não linear típico que é popularmente chamado de resistência negativa, que se caracteriza pela queda da tensão e aumento da corrente após o acendimento (INMAN, 1939). Para uma lâmpada NE2H típica, a tensão de acendimento fica próxima a 60 $\mathrm{V}$, enquanto a tensão de manutenção cai para perto de $50 \mathrm{~V}$. Com o envelhecimento da lâmpada esses valores tendem a aumentar, e podem ser diferentes para lâmpadas néon de outros tamanhos e formatos.

No caso deste experimento as tensões de acendimento e manutenção da lâmpada NE2H têm valor informativo, pois no desenvolvimento apresentado esta lâmpada é utilizada apagada, apenas como sensor. De fato, a lâmpada é usada como um tipo especial de sensor, chamado transdutor, pois converte energia luminosa em energia elétrica.

\section{Efeito Fotoelétrico na lâmpada NE2H}

Qualquer componente eletrônico, provavelmente, não importando sua destinação original, pode ser usado como sensor de uma ou mais grandezas físicas. O que determina seu uso para este fim alternativo é a conveniência (linearidade, sensibilidade, custo, durabilidade, etc.). Dessa forma, não é estranho que uma lâmpada néon possa funcionar como sensor de luz, por exemplo. Partindo dessa intuição, constatou-se experimentalmente que uma lâmpada néon exposta à luz solar produzia uma corrente elétrica entre seus terminais, e que essa corrente variava tanto em módulo quanto em polaridade conforme a posição de seus eletrodos em relação aos 
raios solares. O fenômeno foi constatado também, em graus variados, com a exposição da lâmpada néon à luz provinda de:

a) Lâmpadas incandescentes - comuns e halógenas;

b) Lâmpadas de descarga que emitem luz branca - fluorescentes (mercúrio em baixa pressão), de mercúrio (em alta pressão) e de xenônio (de faróis automotivos);

c) Arcos voltaicos, de uma máquina de solda elétrica;

d) Lasers verde e azul;

e) LEDs verde, azul, branco quente, branco frio, rosa e violeta.

O efeito não pôde ser reproduzido, porém, com a luz emitida por um laser vermelho ou LEDs vermelhos, laranjas e amarelos. Isso sugeriu que o fenômeno estava relacionado à energia dos fótons. Também foi percebida variação na corrente entre lâmpadas néon de diferentes fabricantes expostas à mesma fonte luminosa, sugerindo que não há uniformidade nos materiais das lâmpadas NE2H de diferentes marcas comerciais.

Além disso, segundo a General Electric (1966), a tensão de acendimento dessas lâmpadas se reduz na presença de radiação UV. Em um primeiro momento pode-se imaginar duas razões para isso: a luz UV poderia ionizar diretamente os gases no interior da lâmpada, e/ou induzir a emissão de elétrons pelo metal superficial dos eletrodos (Efeito Fotoelétrico).

A ionização dos gases internos da lâmpada néon, entretanto, não poderia ser responsável pelo surgimento de uma corrente entre seus terminais, pois consistiria simplesmente na liberação de portadores de carga móveis na atmosfera interna da lâmpada, o que reduziria a resistência de isolamento mas não polarizaria os eletrodos, deixando inexplicada a inversão do sentido da corrente elétrica nos terminais conforme o ângulo de incidência da luz. Além disso, o néon tem energia mínima de ionização de aproximadamente $21,5 \mathrm{eV}$, enquanto o argônio ioniza com aproximadamente 15,8 eV (NIST, s/ano). Já os fótons emitidos pelos LEDs de cor violeta - os de maior energia usados no experimento - se situam na fronteira da faixa visível, com comprimentos de onda centrados em $390 \mathrm{~nm}$, se espalhando $30 \mathrm{~nm}$ para mais e para menos deste valor central (NTE, s/ano), avançando para a zona considerada ultravioleta proximal, ou UVA. Portanto, os fótons emitidos por esses LEDs têm energias máximas da ordem de (Eq. 2 e 3):

$$
\begin{aligned}
& E=h \times f \\
& E=h \times \frac{c}{\lambda}
\end{aligned}
$$

sendo:

$\boldsymbol{E}$ a energia máxima dos fótons emitidos pelo LED violeta;

$\boldsymbol{h}$ a constante de Planck;

$c$ a velocidade da luz, e;

$\boldsymbol{\lambda}$ o comprimento de onda mínimo da luz emitida por esse LED. 


$$
\begin{gathered}
E=4,14 \times 10^{-15} \mathrm{eV} . \mathrm{s} \times \frac{3,00 \times 10^{8} \mathrm{~m} / \mathrm{s}}{(390-30) \times 10^{-9} \mathrm{~m}} \\
E=3,45 \mathrm{eV}
\end{gathered}
$$

A energia máxima dos fótons emitidos pelo LED violeta, portanto, tem valor pelo menos três vezes menor que a energia mínima de ionização dos gases no interior da lâmpada néon, sendo possível descartar a ionização direta do néon ou do argônio pela luz dos LEDs usados no experimento.

Já a função trabalho $\left(\mathrm{W}_{0}\right)$ dos metais é menor, e varia aproximadamente entre $2,10 \mathrm{eV}$, para o césio, e 6,35 eV, para a platina (IF USP, s/ano). Como o metal dos eletrodos das lâmpadas néon e o tratamento que é dado às suas superfícies não é divulgado, não se pôde saber de antemão sua função trabalho, e foi preciso solicitar ao Laboratório de Espectroscopia e Microscopia $\mathrm{X}$ (o nome do laboratório foi omitido para garantir o anonimato desta versão sob análise) para que obtivesse imagens dos eletrodos e determinasse sua composição química. A Fig. 2 mostra uma dessas imagens.

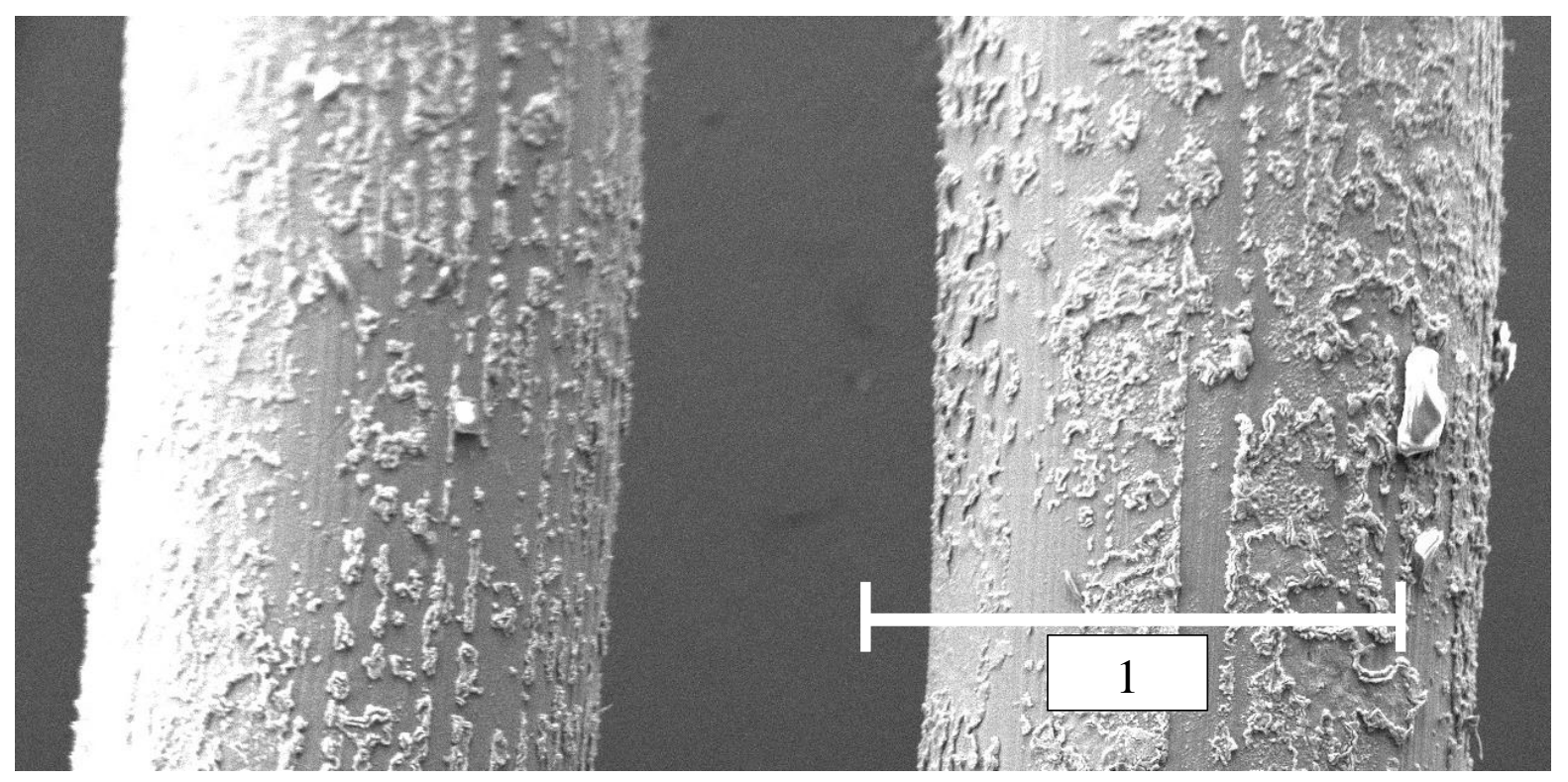

Fig. 2 - Os eletrodos de uma lâmpada néon NE2H. (Fonte: Laboratório Espectroscopia e Microscopia Eletrônica X)

A imagem da Fig. 2 teve ampliação original de 81X. Nos eletrodos, aparecem linhas verticais de trefilação e crostas de uma substância deposta. O formato de ilhas dessa substância sobre a superfície metálica lisa dos eletrodos sugere a deposição de um material sólido com o auxílio de um solvente, que depois evaporou ou foi queimado. A hipótese da queima parece razoável, já que a imagem mostra três ou quatro depósitos maiores que apresentam superfícies lisas, prismáticas ou com aspecto fundido. Tudo isso aponta para a deposição de um sal metálico, seguida de calcinação. O objetivo dessa deposição provavelmente está associado à redução 
da tensão de acendimento, já que este é o principal desafio de engenharia na fabricação das lâmpadas néon (GENERAL ELECTRIC, 1966).

Muitos metais têm baixa função trabalho e poderiam ser aplicados na lâmpada néon, como o sódio $(2,28 \mathrm{eV})$, o potássio $(2,30 \mathrm{eV})$ ou o magnésio $(3,68 \mathrm{eV})$ (IF USP, s/ano), porém, na análise espectroscópica de RX aplicada sobre o produto da raspagem superficial dos eletrodos foi detectada alta concentração de bário - um metal alcalino terroso cuja função trabalho é 2,35 eV (SPEIGHT, 2004). O gráfico da análise espectroscópica aplicada sobre a amostra é apresentado na Fig. 3. No eixo vertical aparecem as contagens medidas - um valor que tem relação com a quantidade relativa de cada substância -, e no eixo horizontal a energia (absoluta) do feixe de RX, em keV. Os materiais correspondentes aos máximos detectados são indicados no próprio gráfico, pelos seus símbolos atômicos.

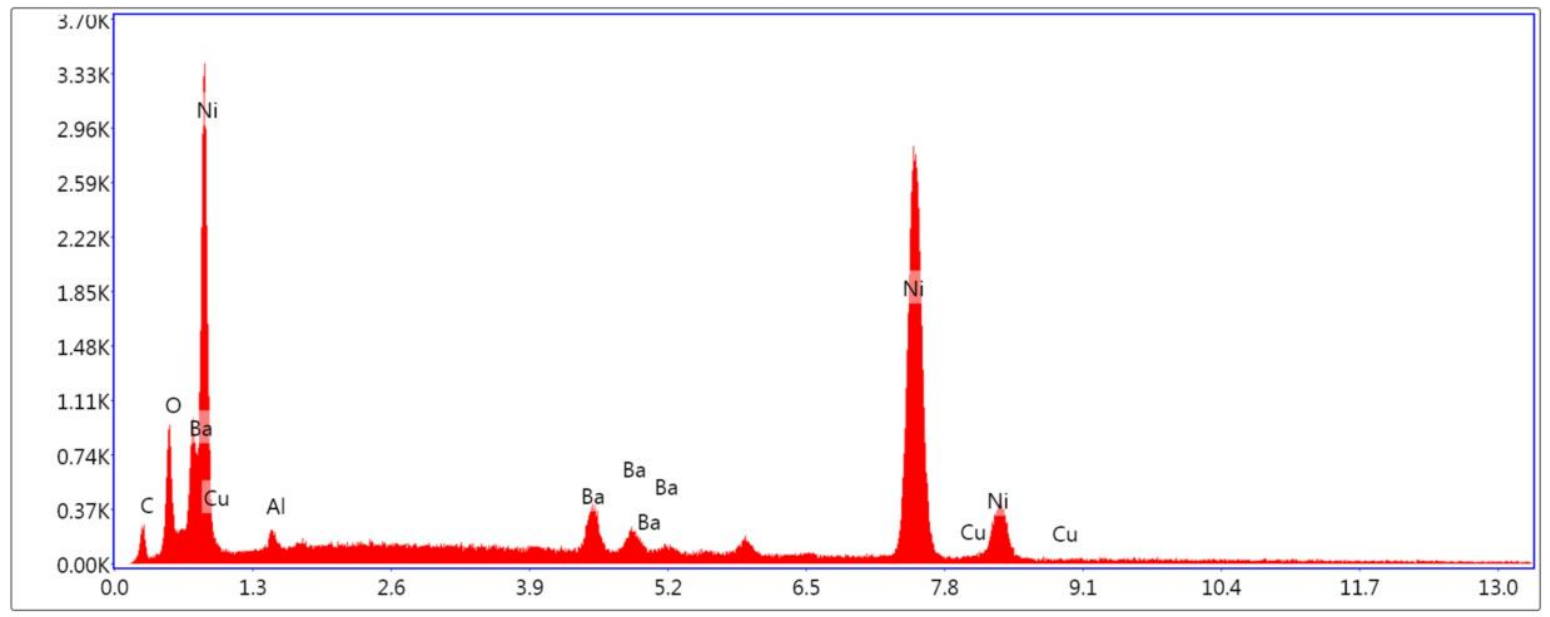

Lsec: 22.30 Cnts 0.000 keV Det: Apollo X-SDD Det

Fig. 3 - Análise espectroscópica por RX dos eletrodos da lâmpada néon, obtido por um Apollo X Silicon Drift Detector. (Fonte: Laboratório de Espectroscopia e Microscopia Eletrônica X)

O níquel, que aparece destacado no gráfico da Fig. 3, pertence ao metal de base do eletrodo. O cobre e o alumínio são resquícios dos fios condutores prensados na peça de níquel. $\mathrm{O}$ oxigênio e o carbono constituem o sal (provavelmente, carbonato de bário - $\mathrm{BaCO}_{3}$ ) utilizado no processo de deposição do bário na superfície dos eletrodos, antes da calcinação. Exceto o bário, nenhum destes elementos químicos é relevante para a ocorrência do Efeito Fotoelétrico sob luz visível.

Dado que os eletrodos da lâmpada NE2H analisada são revestidos por bário, é possível prever que ocorrerá o Efeito Fotoelétrico quando nesses eletrodos incidir luz cujos fótons tenham energia que iguale ou supere a função trabalho do bário $\mathrm{W}_{\mathrm{Ba}}=2,35 \mathrm{eV}$ (IF USP, s/ano). Isso ocorrerá quando o espectro da luz incidente alcançar comprimentos de onda iguais ou inferiores a (Eq. 4): 


$$
\lambda=h \frac{c}{W_{B a}}
$$

sendo:

$\boldsymbol{\lambda}$ o comprimento de onda máximo da luz capaz de extrair elétrons do bário.

$\boldsymbol{h}$ a constante de Planck;

$c$ a velocidade da luz, e;

$\boldsymbol{W}_{\boldsymbol{B} \boldsymbol{a}}$ a função trabalho do bário.

$$
\begin{gathered}
\lambda=4,14 \times 10^{-15} \mathrm{eV} . \mathrm{s} \times \frac{3,00 \times 10^{8} \mathrm{~m} / \mathrm{s}}{2,35 \mathrm{eV}} \\
\lambda=528 \mathrm{~nm}
\end{gathered}
$$

Este comprimento de onda corresponde aproximadamente à cor verde, no centro do espectro visível, o que explica os resultados positivos obtidos na geração de correntes fotoelétricas na lâmpada NE2H a partir de sua exposição às fontes de luz utilizadas.

\section{As bases do experimento}

O experimento realizado foi qualitativo, pois para ser possível uma análise quantitativa seria preciso medir a diferença de potencial gerada na lâmpada néon, o que exigiria um sistema de medição demasiadamente complexo para um desenvolvimento cuja pretensão é ser aplicado no Ensino Básico, pois a resistência de isolamento entre os eletrodos da lâmpada apagada tende ao infinito. Além disso, seria preciso considerar o potencial de contato bário-níquel, pois este potencial produz um deslocamento na medição do potencial de freamento. Como a noção de potencial de contato excede o conteúdo tradicionalmente tratado no Ensino Médio, não foi abordado neste artigo, e o potencial de freamento foi tratado apenas teoricamente. Já a corrente elétrica é mais simples de ser medida e pode ser significativa, pois ela tem sentido definido, módulo proporcional à intensidade da luz incidente e surge apenas para determinados comprimentos de onda dessa luz, como seria esperado no Efeito Fotoelétrico.

No multímetro utilizado neste desenvolvimento - ICEL MD-6111 - a menor escala de corrente contínua é de $200 \mu \mathrm{A}$, com resolução de $0,1 \mu \mathrm{A}$. Como a corrente fotoelétrica gerada pela lâmpada néon sob a luz emitida por LEDs varia entre alguns décimos a algumas dezenas de nanoamperes (nA) não é possível utilizar diretamente aquela escala de corrente para esta medição.

Convenientemente, a menor escala de tensão dos multímetros mais comuns (usualmente, $200 \mathrm{mV}$ com resolução de $0,1 \mathrm{mV}$ ) pode ser utilizada para medições indiretas de correntes elétricas da ordem dos nanoamperes. Para isso, basta dividir a tensão indicada no mostrador pela resistência da escala de tensão do instrumento (usualmente, $10 \mathrm{M} \Omega$ ). Neste caso, para cada $0,1 \mathrm{mV}$ indicado no multímetro a lâmpada estará gerando $0,1 \mathrm{mV} / 10 \mathrm{M} \Omega$, ou seja, 0,01 nA, o que permite medições de correntes com dois ou três algarismos significativos suficientes para este experimento. A maioria dos modelos de multímetros de baixo custo do 
mercado possui uma escala de $200 \mathrm{mV}$ sob resolução de $0,1 \mathrm{mV}$ e resistência de $10 \mathrm{M}$, mas existem modelos de $1 \mathrm{M} \Omega$. Informação sobre a resistência da escala de tensão está contida no manual do instrumento, e também pode ser medida diretamente por intermédio da escala de medição de resistência de outro multímetro.

A proposta inicial do experimento para ensino do Efeito Fotoelétrico consiste em os estudantes, instruídos sobre medições de tensões e correntes elétricas, ligarem uma lâmpada néon a um multímetro digital, na escala de tensão de $200 \mathrm{mV}$, iluminando os eletrodos com a luz de LEDs de diferentes comprimentos de onda, correlacionando essas radiações com as indicações do multímetro, convertidas para corrente elétrica.

O circuito básico do experimento é mostrado na Figura 4. A luz incidente provém de LEDs comuns, de $5 \mathrm{~mm}$ de diâmetro, ligados a uma fonte variável de corrente contínua, ajustada para um valor entre 10 e $30 \mathrm{~mA}$.

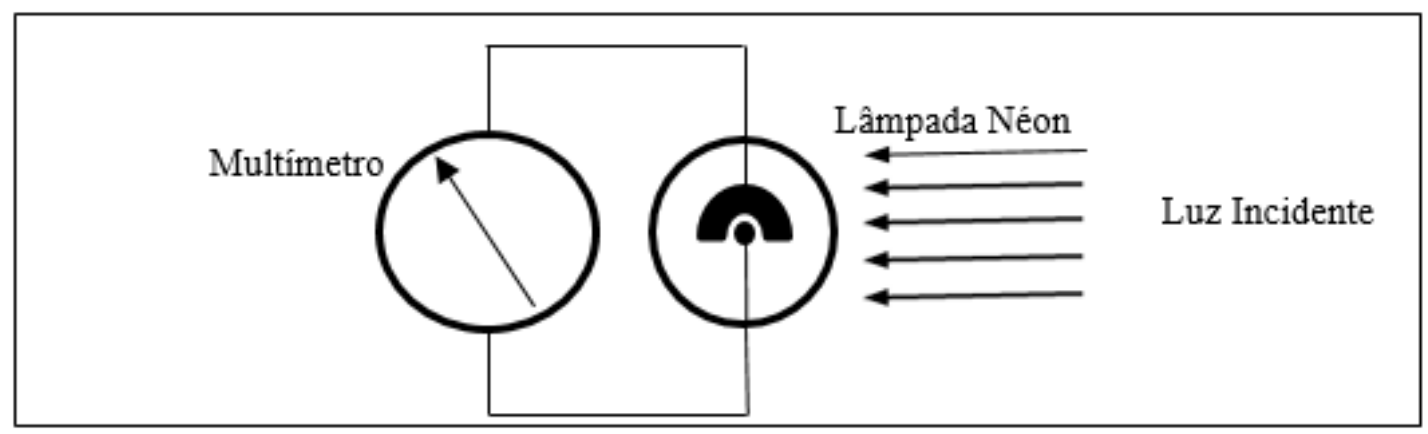

Fig. 4 - Diagrama da montagem básica do experimento (Fonte: os autores).

Instruídos sobre a conversão tensão-corrente, ao realizarem as operações de medição os alunos perceberão que, ao iluminar a lâmpada com a luz emitida por certos LEDs, será gerada corrente cujo módulo e sentido dependem do ângulo de incidência da luz nos eletrodos, assim como da sua intensidade. É importante buscar o comprimento de onda da luz emitida pelo LED utilizado e anotar a maior indicação absoluta de corrente obtida na lâmpada néon, para cada LED.

Estudantes observadores notarão que a corrente pode ser positiva ou negativa, conforme a face interna de um ou outro dos eletrodos esteja mais iluminada, e que o valor máximo absoluto da corrente é obtido quando a face interna de um dos eletrodos é totalmente iluminada, enquanto a face interna do outro eletrodo permanece na sombra. Também é possível perceber que aumentando a corrente sobre o LED, e consequentemente o seu brilho, a corrente fotoelétrica na lâmpada néon aumentará proporcionalmente. Uma representação dessa possibilidade é mostrada na Fig. 5. 


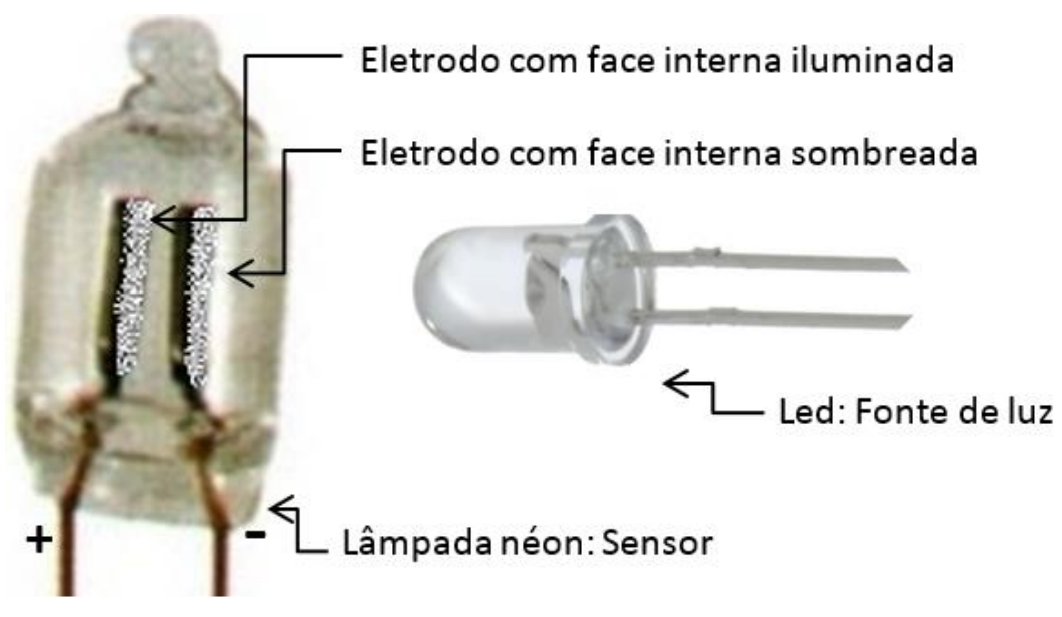

Fig. 5 - Posicionamento da fonte de luz em relação aos eletrodos da lâmpada néon para produção da maior intensidade de corrente fotoelétrica. (Fonte: os autores)

Para um LED com determinada intensidade fixa a maximização da corrente fotoelétrica se dá quando a disposição entre a luz incidente e os eletrodos da lâmpada néon é aquela mostrada na Fig. 5. As faces internas são as superfícies de maior proximidade entre os eletrodos da lâmpada néon e, portanto, constituem-se nas superfícies preferenciais para troca de elétrons. Quando a face interna de um dos eletrodos está mais iluminada que a face interna do outro eletrodo os fotoelétrons podem migrar da superfície mais iluminada para a superfície menos iluminada, produzindo assim uma corrente fotoelétrica. Na hipótese de ambas as faces estarem igualmente iluminadas, a corrente fotoelétrica tende a zero.

Este é um experimento que pode ser utilizado por qualquer professor de física, em acordo com a epistemologia adotada pelo mesmo, pois tanto se presta a experimentos demonstrativos, quanto roteirizados e até investigativos.

Em uma situação hipotética de caráter investigativo e problematizador, por exemplo, perguntas dirigidas aos estudantes podem incentivá-los à busca de respostas. O professor pode perguntar por que razão surgiria uma corrente elétrica entre os eletrodos de uma lâmpada néon exposta à luz, ou por que essa corrente mudaria de sentido ao se iluminar um e, depois, o outro eletrodo. Nesse caso é importante incentivar a emergência de argumentações sobre o fenômeno observado porque essas ações podem gerar novas pesquisas (OLIVEIRA et al., 2010), num ciclo que culmina, em algum momento, em uma compreensão qualitativa inicial do Efeito Fotoelétrico, ou seja, de que a luz pode ser capaz de extrair cargas elétricas da superfície de metais. Novas problematizações, então, podem ser realizadas, fazendo os estudantes entrarem em contato com os conceitos fundamentais desse tópico: função trabalho, energia dos fótons, energia cinética de elétrons, frequência de corte e potencial de freamento.

Num caso típico, com uma lâmpada néon iluminada com um LED violeta alimentado a $20 \mathrm{~mA}$, tensões absolutas máximas da ordem de $50 \mathrm{mV}$ podem ser medidas, resultando em uma corrente absoluta máxima de (Eq. 5): 


$$
i_{f e}=\frac{V_{f e}}{R}
$$

na qual:

Ife é a corrente fotoelétrica absoluta máxima gerada em determinada lâmpada néon exposta à luz de um LED violeta;

$\boldsymbol{V} \boldsymbol{f} \boldsymbol{e}$ é o máximo valor absoluto da tensão indicada na escala de $200 \mathrm{mV}$ do multímetro ligado à lâmpada néon iluminada pelo LED violeta;

$\boldsymbol{R}$ é a resistência de entrada da escala de medição de tensão de $200 \mathrm{mV}$ do multímetro utilizado.

$$
\begin{gathered}
i_{f e}=\frac{50 \times 10^{-3} \mathrm{~V}}{10 \times 10^{6} \Omega} \\
i_{f e}=5 \mathrm{nA}
\end{gathered}
$$

Ao realizarem esta experimentação, talvez associada a reflexões, argumentações e pesquisas, espera-se que os estudantes elaborem um entendimento básico sobre o Efeito Fotoelétrico, a lâmpada néon e as técnicas de medição.

\section{Informações complementares ao experimento}

Neste desenvolvimento foram usados LEDs de nove cores diferentes, todos de $5 \mathrm{~mm}$ de diâmetro e invólucro transparente, da marca NTE, com $20 \mathrm{~mA}$ de corrente nominal. Foram eles: vermelho (NTE 30137), laranja (NTE 30040), amarelo (NTE 30039), verde (NTE 30038), azul (NTE 30043), rosa (NTE 30121), branco quente (NTE 30045), branco frio (NTE 30149) e violeta (NTE 30128). Mas efeitos semelhantes podem ser obtidos com LEDs de outras marcas.

Para variar a intensidade luminosa dos LEDs estes foram ligados diretamente a uma fonte de alimentação ajustável, com indicação de tensão e corrente. Essas fontes são comuns em laboratórios didáticos, mas poderia ser usado, também, o circuito da Fig. 6, contendo uma bateria de $9 \mathrm{~V}$, um miliamperímetro, um resistor de $220 \Omega$ e um potenciômetro de fio de $1 \mathrm{k} \Omega$. Com o auxílio da fonte variável ou do circuito mostrado na Figura 6, os estudantes podem variar a intensidade da luz emitida pelos LEDs, observando como essa intensidade influencia a corrente fotoelétrica na lâmpada néon.

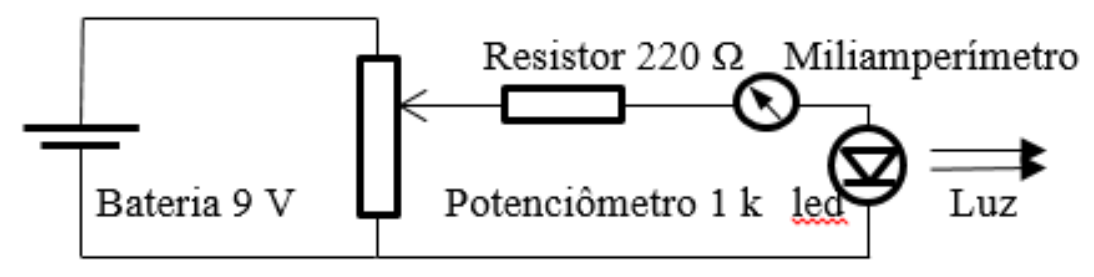

Fig. 6-Fonte alternativa para acendimento e ajuste de intensidade de emissão de luz pelos LEDs. (Fonte: os autores) 
A luz emitida pelos LEDs vermelhos, laranjas e amarelos não produz indicação de corrente, ao contrário do que ocorre com a luz dos demais LEDs, independentemente da intensidade. De fato, a corrente fotoelétrica medida não tem um significado simples. Caso se decida a avançar até esse nível de detalhamento, o professor pode calcular, a partir da corrente fotoelétrica, quantos fotoelétrons são capturados no eletrodo escurecido a cada segundo, em dada situação experimental. Ter noção da ordem de grandeza dessa corrente ajuda a trazer o fenômeno para mais próximo do cotidiano dos estudantes.

Neste desenvolvimento, a lâmpada foi fixada em uma pequena ripa de madeira, e os nove LEDs foram soldados em série sobre um transferidor plástico, a cada 40 graus. O transferidor foi preso à mesma ripa, de maneira que fosse possível girá-lo, posicionando um LED de cada vez exatamente à frente da lâmpada néon. Optou-se por essa montagem para se obter um gráfico de corrente fotoelétrica versus posição de cada LED, sendo este gráfico elucidativo para a construção de uma ideia qualitativa do fenômeno. Os LEDs foram ligados a uma fonte, permanecendo todos acesos durante o experimento. Na Fig. 7 é mostrada a montagem em funcionamento.

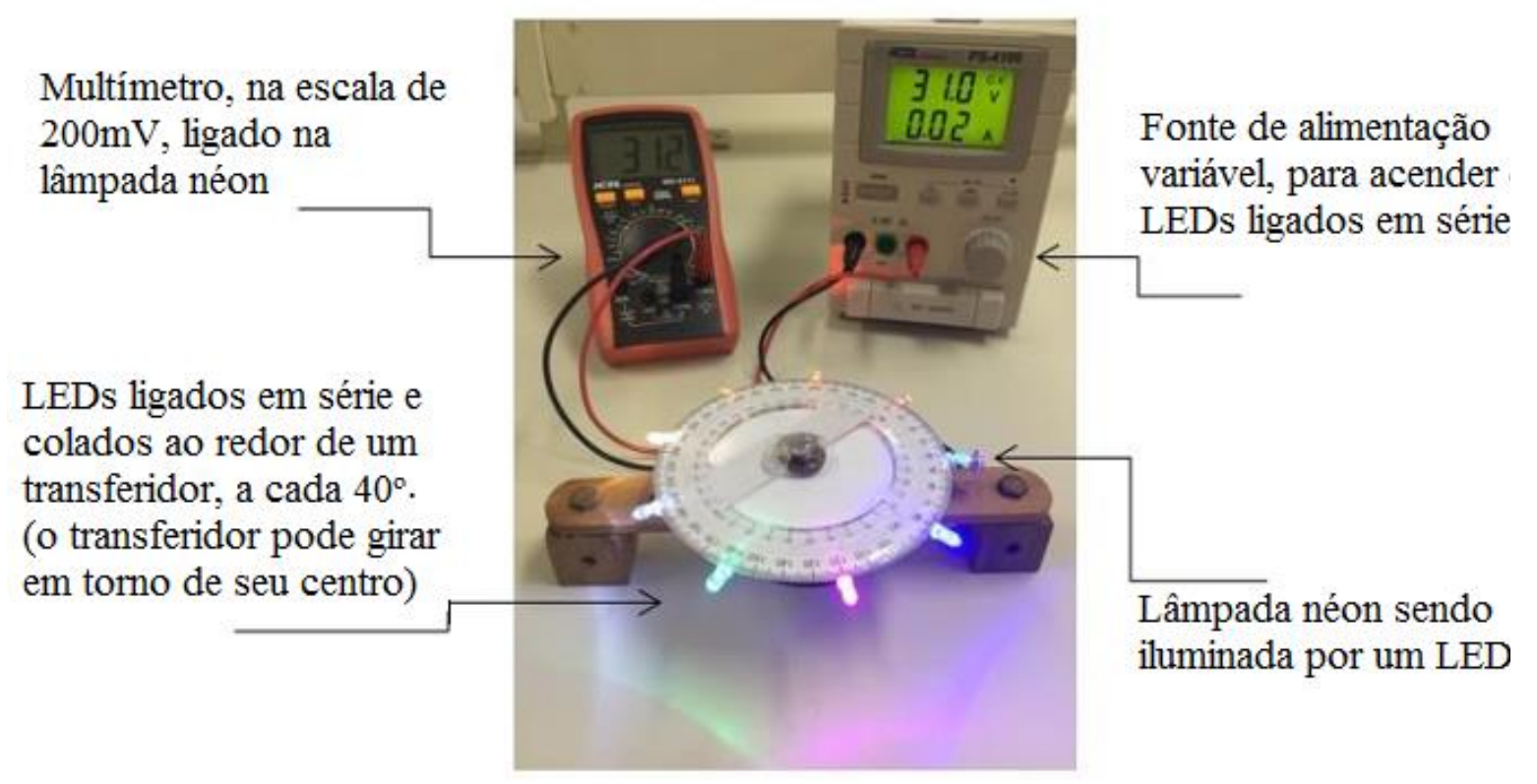

Fig. 7 - Montagem do experimento, em operação. (Fonte: os autores)

Como resultado das medições feitas com a montagem foi possível construir um gráfico relacionando a posição angular do transferidor com a corrente fotoelétrica gerada na lâmpada néon, que é mostrado na Fig. 8. Aproximadamente, em $0^{\circ}$ está posicionado o LED vermelho, em $40^{\circ}$ está o LED laranja, em $80^{\circ}$ está o LED amarelo, em $120^{\circ}$ está o LED branco quente, em $160^{\circ}$ está o LED verde, em $200^{\circ}$ está o LED rosa, em $240^{\circ}$ está o LED branco frio, em $280^{\circ}$ está o LED azul e em $320^{\circ}$ está o LED violeta. 


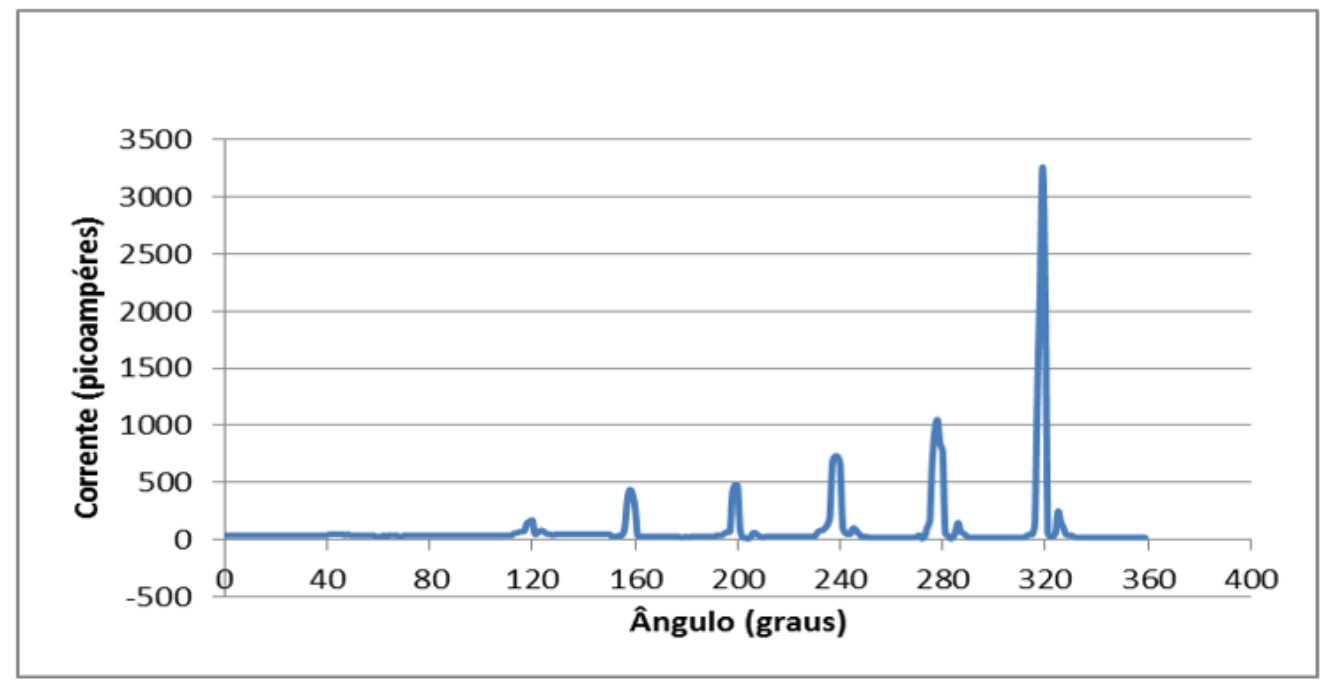

Fig. 8 - Gráfico da corrente fotoelétrica gerada na lâmpada néon em função da rotação do transferidor, para os LEDs alimentados com $20 \mathrm{~mA}$. (Fonte: os autores)

Do gráfico da Fig. 8 é possível depreender que há uma dependência da corrente fotoelétrica gerada na lâmpada néon em relação ao comprimento de onda da luz emitida pelos LEDs. As curvas espectrais de emissão dos LEDs utilizados são apresentadas na Fig. 9 (NTE, 2016). Os LEDs vermelho (660 nm), laranja (620 nm), amarelo $(585 \mathrm{~nm})$, verde $(540 \mathrm{~nm})$, azul (465 nm) e violeta (405 nm) emitem um espectro relativamente estreito, ao redor de um único comprimento de onda, enquanto os LEDs branco quente, rosa e branco frio emitem um espectro largo, com picos em dois comprimentos de onda distintos. O LED branco quente tem picos de emissão em $460 \mathrm{~nm}$ e $580 \mathrm{~nm}$. O LED rosa tem picos de emissão em $450 \mathrm{~nm}$ e $605 \mathrm{~nm}$. O LED branco frio tem picos de emissão em $465 \mathrm{~nm}$ e $585 \mathrm{~nm}$ (ibidem).

Com a ajuda da fonte variável foi alterada a intensidade da luz emitida pelos LEDs para avaliação do efeito que isso produziria na corrente fotoelétrica, reconstruindo o gráfico mostrado na Fig. 8. Para isso, foram aplicadas correntes de acionamento dos LEDs de $10 \mathrm{~mA} \mathrm{e}$ $30 \mathrm{~mA}$, além dos $20 \mathrm{~mA}$ nominais. Houve acentuada variação no valor absoluto das correntes medidas sem, contudo, haver variação apreciável na aparência do gráfico, que manteve-se topologicamente estável.

O comportamento da corrente fotoelétrica na lâmpada néon é qualitativamente compatível com o esperado para o comprimento de onda de corte do bário, calculado em $528 \mathrm{~nm}$ a partir da sua função trabalho de 2,35 eV (IF USP, s/ano), para todos os LEDs utilizados. A única exceção é o LED verde, cujo centro de emissão é $540 \mathrm{~nm}$. Rigorosamente, este LED não produziria o Efeito Fotoelétrico sobre o bário, pois os fótons emitidos por ele teriam energia menor do que a necessária. No experimento, porém, há corrente fotoelétrica. Isso decorre do espraiamento do espectro de emissão do LED verde, que abrange comprimentos de onda um pouco menores, que alcançam os $528 \mathrm{~nm}$, como se pode ver no gráfico GREEN da Fig. 9. 

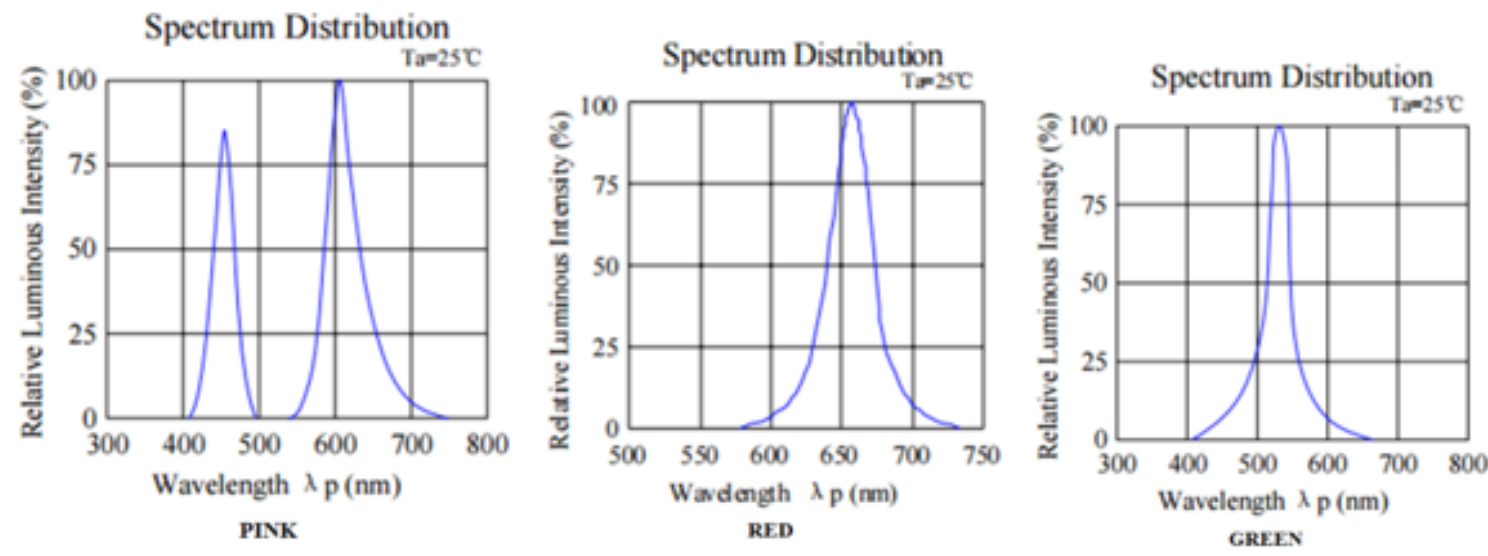

Spectrum Distribution
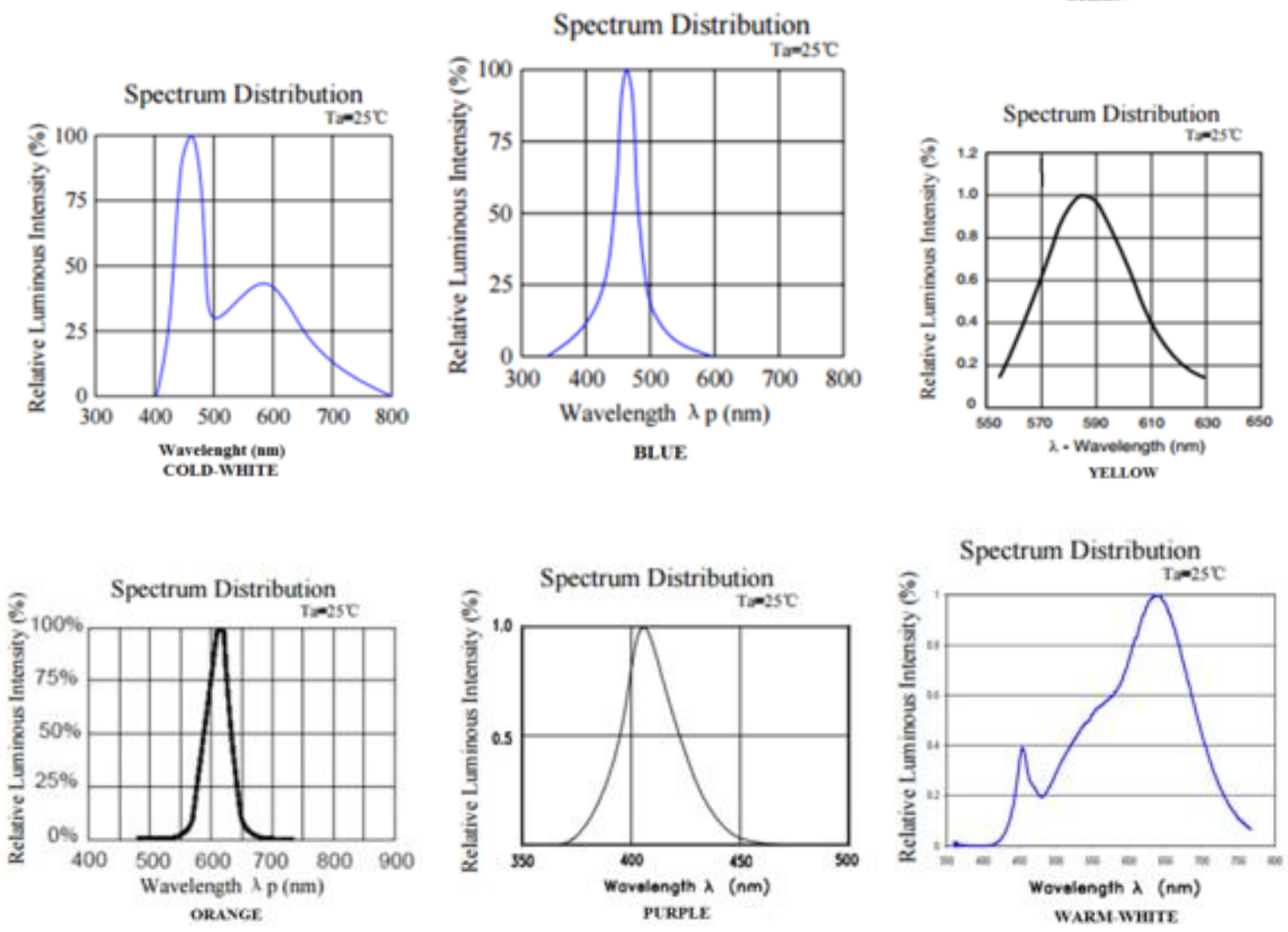

Fig. 9 - Distribuição espectral da luz dos LEDs usados no experimento. (Fonte: NTE, 2016)

Ainda na Fig. 8 é possível perceber um pequeno mas consistente pico na corrente fotoelétrica logo depois do pico principal, que ocorre quando cada LED passa pela frente da lâmpada néon. Esse pico secundário se deve ao posicionamento relativo do LED e da lâmpada néon. Para que a montagem tivesse sucesso foi preciso rotacionar levemente a lâmpada para que o plano dos seus eletrodos não fosse coincidente com o plano dos eixos transferidor-lâmpada, evitando assim que cada LED, ao se voltar exatamente para o centro da lâmpada, ficasse contido nesse mesmo plano. Se isso acontecesse, o eletrodo da lâmpada néon que estivesse mais próximo do LED causaria sombra no eletrodo mais distante, e o Efeito Fotoelétrico seria minimizado. Um esquema dessa estratégia é mostrado na Fig. 10, visto de cima. 


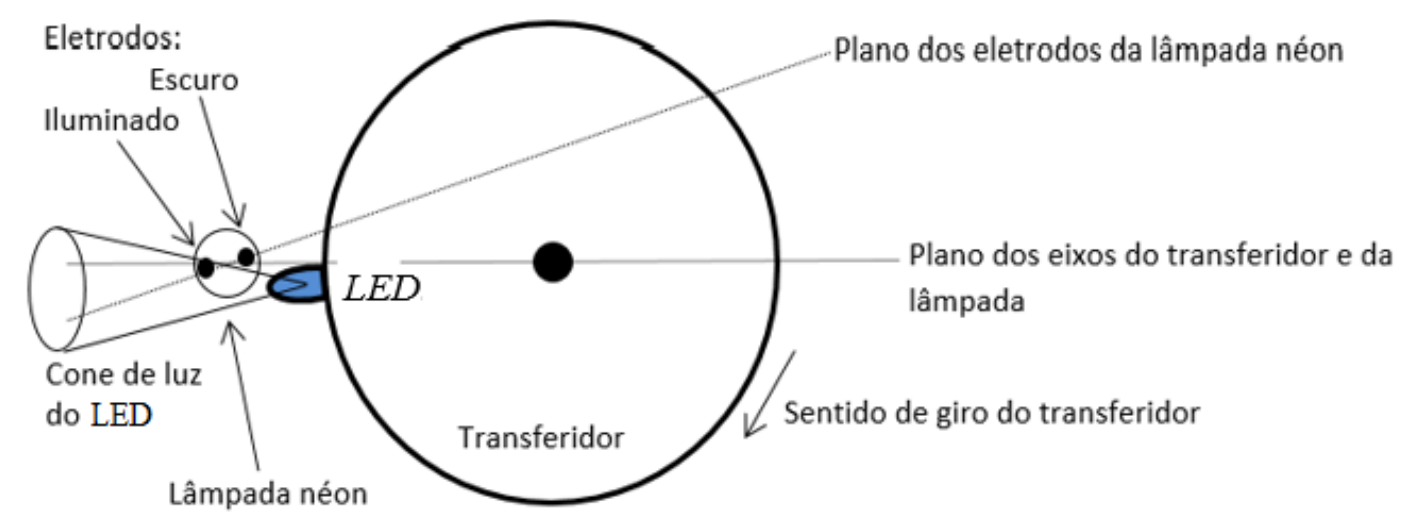

Fig. 10 -Detalhe do desvio no alinhamento lâmpada-transferidor para garantir que um eletrodo não faça sombra sobre o outro quando a lâmpada é iluminada pelo LED. (Fonte: os autores)

Com esse desvio, enquanto o transferidor é rotacionado, cada LED se aproxima da lâmpada, tendo sua luz dirigida primeiramente para a face interna do eletrodo mais distante, produzindo uma intensa liberação de elétrons, enquanto o eletrodo mais próximo permanece relativamente escuro, capturando esses elétrons e gerando um grande pico de corrente fotoelétrica. Com a continuidade do giro, cada LED passa pela lâmpada e sombreia o eletrodo mais distante, para logo em seguida iluminá-lo novamente, agora em sua região lateral, produzindo um segundo, mas pequeno pico de corrente fotoelétrica. Esses dois picos podem ser vistos com clareza na Fig. 8.

\section{Conclusões}

O presente artigo procurou apresentar um experimento de baixa complexidade, alto potencial para contextualização, seguro e de baixo custo que pudesse ser utilizado no ensino de física do Ensino Médio, especificamente o Efeito Fotoelétrico. Esta proposição se originou no entendimento de que as alternativas experimentais usuais para o ensino deste conteúdo podem ser relativamente problemáticas, seja pelo preço proibitivo dos conjuntos prontos comercializados pelas indústrias de equipamentos didáticos, seja pelos riscos das montagens que utilizam lâmpadas que emitem altas intensidades de luz ultravioleta, seja pela dependência da existência de luz solar direta das montagens que envolvem eletroscópios e folhas de zinco. Além disso, alguns desses experimentos podem exigir um exercício mental mais complexo do que o apresentado neste artigo, especialmente quando a interpretação dos resultados envolve a compreensão de mecanismos indiretos de funcionamento, como amplificadores eletrônicos, por exemplo.

A expectativa é que os professores de física possam contar com mais esta opção experimental para o ensino do Efeito Fotoelétrico, que é um conteúdo que faz parte do contexto da Física Moderna e vem sendo exigido com frequência nos vestibulares e no ENEM. Os autores 
se colocam à disposição para atender e responder individualmente os colegas que tiverem quaisquer dúvidas sobre o experimento aqui descrito, bastando para isso utilizarem os e-mails disponibilizados no artigo.

\section{Referências bibliográficas}

ARRUDA, S. M.; TOGINHO FILHO, D. O. Laboratório caseiro de física moderna. Caderno Brasileiro de Ensino de Física, Florianópolis, v. 21, p. 390-394, 1991. Disponível em: <https://periodicos.ufsc.br/index.php/fisica/article/view/10028>. Acesso em: 23 abr. 2017.

BARROS, M. A.; SOARES, J. M. S. Contribuições teóricas e abordagens históricas do Efeito Fotoelétrico. Revista Sustinere, v. 4, n. 2, p. 221-232, 2017. Disponível em: <http://www.epublicacoes.uerj.br/index.php/sustinere/article/view/26216>. Acesso em: 03 jun. 2017.

BERG, H. Johann Wilhelm Ritter-the founder of scientific Electrochemistry. Review of Polarography, v. 54, n. 2, p. 99-103, 2008. Disponível em: <https://www.jstage.jst.go.jp/article/revpolarography/54/2/54_2_99/_article/-char/ja/>. Acesso em: 26 jun. 2017.

CARRASCOSA, J.; GIL-PÉREZ, D.; VILCHES, A.; VALDÉS, P. Papel de la actividad experimental em la educación científica. Caderno Brasileiro de Ensino de Física, v. 23, n. 2, p. 157-181, ago. 2006. Disponível em: <http://roderic.uv.es/handle/10550/54191〉. Acesso em: 24 mai. 2017.

CERNICCHIARO, Geraldo et al. Tópicos Experimentais em Física Moderna. Rio de Janeiro: CBPF-MCT, 2006. Disponível em: <http://mesonpi.cat.cbpf.br/e2006/extensaoensinodefisica/pdf_e3/ManualTopicosFisicaModernaEscolaCBPF06.pdf>. Acesso em: 17 jun. 2017.

GIL-PÉREZ, D. Contribuición de la Historia y de la Filosofía de las Ciencias al desarrollo de un modelo de enseñanza/aprendizaje como investigación. Enseñanza de las Ciencias, v. 11, n. 2, p. 197-212, 1993. Disponível em: <http://www.raco.cat/index.php/Ensenanza/article/download/21204/93254>. Acesso em: 18 mar. 2017.

IF USP - Instituto de Física da Universidade de São Paulo. Função trabalho de alguns metais. Sem ano. Disponível em: <fep.if.usp.br/ profis/experimentando/diurno/downloads/Tabela\% 20de $\% 20$ Funcoes $\% 20$ Trabalho\%20de\%20Alguns\%20Metais.pdf $>$. Acesso em: 26 jul. 2016.

INMAN, G. E. Characteristics of fluorescent lamps. Thirty Second Annual Convention of the Illuminating Engineering Society, Minneapolis, Minnesota, v. 3, n. 3, p. 3, 1939. Disponível em: <http://www.brikbase.org/sites/default/files/ies_045.pdf>. Acesso em: 12 mai. 2017.

LEYSHON, W. A. Characteristics of discharge tubes under flashing conditions as determined by means of the cathode ray oscillograph. Proceedings of the Physical Society, v. 42, n. 3, p. 
157, 1930. Disponível em: <http://iopscience.iop.org/article/10.1088/0959-5309/42/3/302/ meta>. Acesso em: 03 jun. 2017.

MACKENZIE, F. T.; MACKENZIE, J. A. Our changing planet. Prentice-Hall, Upper Saddle River, New Jersey, 1995. p. 288-307.

MANGILI, A. I. Heinrich Rudolph Hertz e a descoberta do efeito fotoelétrico: Um exemplo dos cuidados que devemos ter ao utilizar a história da ciência na sala de aula. História da Ciência e Ensino: construindo interfaces. v. 6, p. 32-48, 2012. Disponível em: <http://www.joinville.udesc.br/portal/professores/fragalli/materiais/Heinrich_Rudolph_Hertz _e_a_descoberta_do_efeito_fotoeletrico.pdf >. Acesso em: 23 mai. 2017.

MARTINS, A. F. P. História e Filosofia da Ciência no ensino: Há muitas pedras nesse caminho. Caderno Brasileiro de Ensino de Física, v. 24, n. 1, p. 112-131, 2008. Disponível em: <https://periodicos.ufsc.br/index.php/fisica/article/download/6056/12761>. Acesso em: 19 mar. 2017.

MENEGOTTO, J. C.; ROCHA FILHO, J. B. Atitudes de estudantes do Ensino Médio em relação à disciplina de Física. Revista Electrónica de Enseñanza de las Ciencias, v. 7, n. 2, p. 298-312, 2008. Disponível em: <https://reec.uvigo.es/volumenes/volumen7/ART2_Vol7_N2. pdf>. Acesso em: 18 mai. 2017.

NIAZ, M.; KLASSEN, S.; McMILLAN, B.; METZ, D. Reconstruction of the history of the photoelectric effect and its implications for general physics textbooks. Science Education, v. 94, n. 5, p. 903-931, 2010. Disponível em: <http://onlinelibrary.wiley.com/doi/10.1002/sce. 20389/full>. Acesso em: 12 jun. 2017.

NIST. National Institute of Standards and Technology. NIST Atomic Spectra Database Ionization Energies Form. Disponível em: <https://physics.nist.gov/PhysRefData/ASD/ionEnergy.html>. Acesso em: 20 jul. 2017.

NTE Electronics Inc. Data Sheet LED indicator 5 $\mathbf{m m}$. Disponível em: <http://www.nteinc.com/specs/30100to30199/pdf/nte30128.pdf>. Acesso em: 28 jul. 2016.

OKUN, L. B. Energy and Mass in Relativity Theory. Singapore: World Scientific, p. 216, 2008. Disponível em: <https://books.google.com.br/books?hl=pt-BR\&lr=\&id=vX1pDQAAQ BAJ\&oi=fnd\&pg=PA215\&dq=lightquanta+photon+1928\&ots=17W9OoqAkO\&sig=At-vOK wEWGMniVDcWAMfX1lvojk>. Acesso em: 29 jun. 2017.

OLIVEIRA CARDOSO, S. O.; DICKMAN, A. G. Simulação computacional aliada à teoria da aprendizagem significativa: uma ferramenta para ensino e aprendizagem do efeito fotoelétrico. Caderno Brasileiro de Ensino de Física, v. 29, p. 891-934, 2012. Disponível em: <https://periodicos.ufsc.br/index.php/fisica/article/view/22109>. Acesso em: 29 jun. 2017. 
OLIVEIRA, M. et al. Práticas experimentais de Física no contexto do ensino pela pesquisa: uma reflexão. In: ROCHA FILHO, J. B. Ensino de Física: falhas e soluções. Porto Alegre: EDIPUCRS, 2010, p. 101.

OLIVEIRA, R. A.; SILVA, A. P. B. William Herschel, os raios invisíveis e as primeiras ideias sobre radiação infravermelha. Revista Brasileira de Ensino de Física, v. 36, n. 4, 2014. Disponível em: <http://www.academia.edu/download/35249115/OLIVEIRA_SILVA_herschel_ e_os_raiso_invisiveis_v_36_n_4_4603_RBEF.pdf>. Acesso em: 20 jun. 2017.

OSTERMANN, F.; RICCI, T. S. F. Conceitos de física quântica na formação de professores: relato de uma experiência didática centrada no uso de experimentos virtuais. Caderno Brasileiro de Ensino de Física, v. 22, n. 1, p. 9-35, 2005. Disponível em: <https://periodicos.ufsc.br/index.php/fisica/article/download/6392/5917>. Acesso em: 23 jun. 2017.

PARANHOS, R. R. G.; LOPEZ-RICHARD, V.; PIZANI, P. S. Lâmpada de Hg para experimentos e demonstrações de física moderna: introdução ao efeito fotoelétrico e outros tópicos. Revista Brasileira de Ensino de Física, v. 30, n. 4, p. 4502, 2008. Disponível em: <http://www.scielo.br/pdf/rbef/v30n4/v30n4a11>. Acesso em: 12 dez. 2016.

ROCHA FILHO, J. B.; SALAMI, M. A.; HILLEBRAND, V. Construção e caracterização de uma célula fotoelétrica para fins didáticos. Revista Brasileira de Ensino de Física, São Paulo, v. 28, n. 4, p. 555-561, 2006. Disponível em: <http://www.scielo.br/pdf/\%0D/rbef/v28n4/ a18v28n4.pdf>. Acesso em: 30 jan. 2017.

SILVA, F. N. Construção de aparato experimental para demonstração do efeito fotoelétrico no ensino de ciências. 2015. 31 f. Monografia (Licenciatura em Ciências Naturais) Universidade de Brasília, Planaltina, DF, 2015.

SILVA, N. C. Laboratório virtual de física moderna: atenuação da radiação pela matéria. Caderno Brasileiro de Ensino de Física, v. 29, n. 3, p. 1206-1231, 2012. Disponível em: <https://periodicos.ufsc.br/index.php/fisica/article/view/25283>. Acesso em: 26 jun. 2017.

SOARES, J. M. S. Análise da história do Efeito Fotoelétrico em livros didáticos de Física para graduação. 2016. 87 f. (Dissertação) - Programa de Pós-Graduação em Ensino de Ciências e Educação Matemática PPGECEM. Universidade Estadual da Paraíba. 2016. Disponível em: <http://tede.bc.uepb.edu.br/jspui/bitstream/tede/2623/2/PDF\%20-\%20Joana\%20Menara \%20Souza\%20Soares.pdf>. Acesso em: 13 jun. 2017.

SPEIGHT, J. Lange's Handbook of Chemistry, 16th ed. McGraw-Hill Professional: Boston, MA, 2004.

VEIT, E. Â.; THOMAS, G.; FRIES, S. Z.; AXT, R.; FONSECA, L. O efeito fotoelétrico no segundo grau via microcomputador. Caderno Catarinense de Ensino de Física, Florianópolis, 
v.4, n.2, agosto de 1987. Disponível em: <https://periodicos.ufsc.br/index.php/fisica/article/download/7850/7219>. Acesso em: 05 mar. 2017.

UNICAMP. Tipos de lâmpadas. Instituto de Artes. Disponível em: <http://www.iar.unicamp.br/lab/luz/ld/L\%E2mpadas/Fontes_Lumin.pdf>. Acesso em: 15 set. 2016.

WHEATON, B. R. Philipp Lenard and the photoelectric effect, 1889-1911. Historical Studies in the Physical Sciences, v. 9, p. 299-322, 1978. Disponível em: <http://www.jstor.org/stable/27757381>. Acesso em: 26 jun. 201 